\title{
Arthroscopic Suture Anchor Design Finite Element Study
}

\author{
Mai Ayoub ${ }^{1 *(D)}$, Mohamed El-Anwar ${ }^{1}$ (D) M. I. Negm ${ }^{2}$ \\ ${ }^{1}$ Department of Mechanical Engineering, National Research Centre, Cairo, Egypt; ${ }^{2}$ Department of Mechanical Engineering, \\ Faculty of Engineering, Al-Azhar University, Cairo, Egypt
} Citation: Ayoub M, El-Anwar M, Negm MI. Arthroscopic Suture Anchor Design Finite Element Study. Open Access
Maced J Med Sci. 2021 Jul 22; 9A:562-566. https://doi.org/10.3889/oamjms.2021.6409 Keywords: Finite element analysis; Design; Arthroscopic
anchors; Suture eyelet Correspondence: Mai Ayoub, Department of Mechanica Engineering, National Research Centre, Egypt. E-mail: maifayez.mf86@gmail.com Received: 07-May-202 Revised: 11-Jun-2021
Accepted: 12-Jul-2021
Copyright: $\odot 2021$ Mai Ayoub, Mohamed El-Anwar, Funding: This research did not receive any financial Competing Interests: The authors have declared that no competing interests exist. Open Access: This is an open-access article distributed under the terms of the Creative Commons Attribution-

\begin{abstract}
AIM: This in-vitro study investigated arthroscopic suture anchors' main design parameters effect on surrounding bone.

METHODS: Thirty-dimensional arthroscopic suture anchor designs' models were created on engineering CAD software by changing thread profile, pitch, and anchor tip profile as design parameters. These models were imported into ANSYS Workbench for finite element analysis. Bone was simplified and modeled as two coaxial cylinders. Tensile vertical load of $300 \mathrm{~N}$, and oblique at $45^{\circ}$ to the vertical axis, were applied to each model as two loading conditions while the simplified bone base was fixed in place as a boundary condition.

RESULTS: The finite element analyses on all models under both loading conditions showed stresses within physiological limits on bone. Trapezoidal teeth and inclined cut teeth designs showed the lowest values of stresses and deformations respectively on the bone under oblique loads, while curved tooth and square tooth designs showed the lowest values of stresses and deformations respectively on the bone under vertical loads. General ascending or descending trend was recorded by increasing pitch from 1.2 to 1.5 to $1.8 \mathrm{~mm}$ on the total deformation and maximum Von Mises stress on bone and anchor body. Tapered tip slightly increased bone and anchor stresses.

CONCLUSION: Arthroscopic anchors thread profile has minor affect on cortical bone behavior. Trapezoidal teeth square tooth, and inclined cut teeth profiles showed the lowest values of stresses and deformations on cortical bone. Increasing thread pitch of arthroscopic suture anchors increases or decreases stress on the bone, and anchor body according to thread profile edges. Anchor tip profile negligibly affects both deformations and stresses on bone and anchor body.
\end{abstract}

Introduction

Suture anchors are very helpful fixation mechanisms for bone fixation with tendons and ligaments. They are made up of; (1) Anchor, which is embedded into the bone. This may be a screw mechanism or an interference suit (like a rawl bolt used in DIY) [1]. They could be made of metal or biodegradable material; (which dissolves in the body over time) [2], [3]. The Eyelet - is the hole or ring in which the suture passes through the anchor. This is connecting the anchor to the suture [2]. The suture is attached to the anchor by means of the anchor eyelet. It could also be a non-absorbable material or biodegradable material. The Suture anchor is a self-adhesive titanium implant that comes preloaded with high-strength HiFi sutures. It helps for more anchorage points and being able to distribute the load more uniformly around the tendon. On the other hand, it serves as a versatile stitching alignment [4], [5].

Arthroscopic anchors designs have different parameters including length, diameter, tip angles (taper, cutting, etc. [6] by changing one or more from those parameters we can find the optimum design(s) for a specific case. Most of these researches' results are protected by patents [7], [8], [9], [10].
The modern kits of arthroscopic implants are single use, that it contains The modern arthroscopic implant kits are single-use, containing (1) a hollow plastic handle (polyethylene) with one internal threaded end, (2) a titanium tube (threaded end at the handle and outer hexagon end), (3) one or two HiFi fibers, each one meter long, to be knitted between anchors, (4) an arthroscopic anchor. Assembling the plastic handle and Titanium tube by thread resulted in anchor driver [11].

Arthroscopic anchors can be produced of a wide variety of materials, from stainless steel, pure titanium, titanium alloys, and biocomposite materials. Austenitic types with specific compositions for this specific application are the three grades listed in the standard requirements. These materials are tested according to EN ISO 10993 and EN ISO 14971 for biocompatibility and safety. Chromium-NickelMolybdenum alloyed austenitic stainless steel used by BIOTEK implants complies with international standards ISO 5832-1 and ASTM F138/ASTM F139. The manufacturing of such instruments includes highprecision equipment, including high-performance CNC machines, electropolishing, laser part detection, ultrasonic cleaning and passivation, and state-of-theart inspection laboratories [12], [13], [14], [15], [16]. 
In this study, three major Suture Anchor parameter designs were investigated as; Thread type, pitch, and tip angle via finite element analysis. Laboratory testing for the prototypes to validate the theoretical study results against the in-vitro ones.

\section{Materials and Methods}

Thirty three-dimensional geometric models for suture anchor of $30 \mathrm{~mm}$ length and $10 \mathrm{~mm}$ diameter were created by "SolidWorks" ver.2017 (Dassault Systèmes SolidWorks Corp., France) to evaluate the effect of three design parameters (Figure 1).

a) Thread profile (curved tooth, inclined cut tooth, trapezoidal tooth, sawtooth, and Square tooth),

b) Pitch length $(1.2,1.5$, and $1.8 \mathrm{~mm})$,

c) Tip profile (chamfered and tapered with $45^{\circ}$ ).

The proposed suture anchors 3D models were transferred to ANSYS Workbench Version 16 (ANSYS Inc., Canonsburg, PA, USA) as STEP files to be analyzed. Where bone geometry was simplified and simulated as two coaxial cylinders. The inner one represents the spongy bone (diameter $14 \mathrm{~mm}$ and height $32 \mathrm{~mm}$ ) which fills the internal space of the outer cylinder (shell of $2 \mathrm{~mm}$ thickness) that represents cortical bone (diameter $18 \mathrm{~mm}$ and height $36 \mathrm{~mm}$ ) as presented in Figure 2. These models after assembly were subjected to $300 \mathrm{~N}$ [17], [18], [19] tensile vertical force located at eyelet (fibers resting) and oblique at $45^{\circ}$ from the vertical axis. The base of the hollow cylinder representing the cortical bone was set to be fixed as a boundary condition. The final model results were verified against previous studies [17], [18], [19].

Linear static analysis was performed on a Workstation HP Z820, with Dual Intel Xeon E5-2660, 2.2 GHz processors, 64GB RAM. Figures 2, illustrate example for detailed drawing for anchor tip profile, and ANSYS screenshots show one final model and meshed one prior to analysis.

\section{Results}

The finite element analyses on all models under both loading conditions showed stresses within physiological limits on bone. Tons of graphical representations were obtained for each model component, that a sample results for model curved teeth of $1.5 \mathrm{~mm}$ pitch and tapered tip under tensile vertical load of $300 \mathrm{~N}$ are presented in Figure 3.

Comparing different thread types among tip profile and loading direction is presented in Figure 4, indicated the superiority of curved then square thread

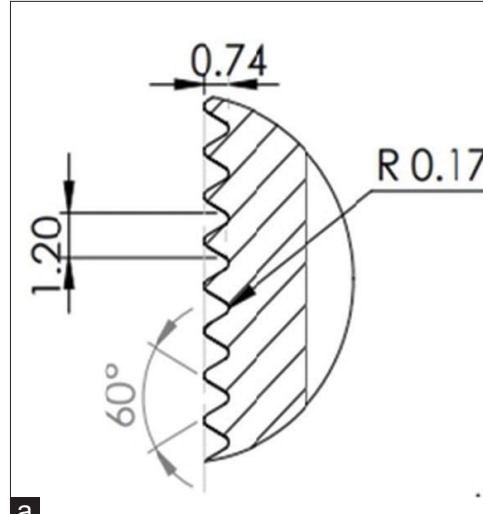

a

b

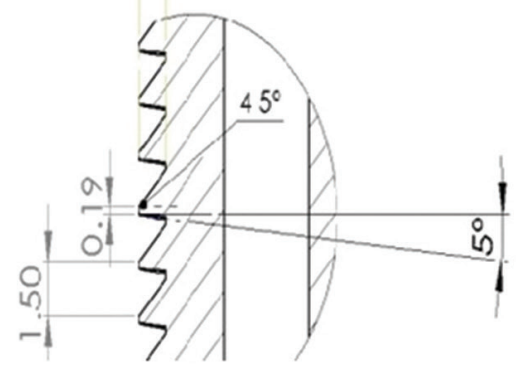

c

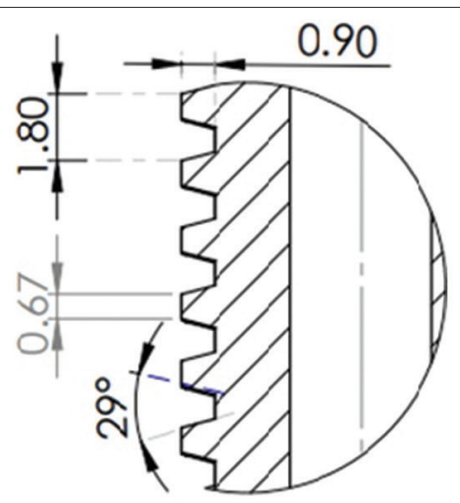

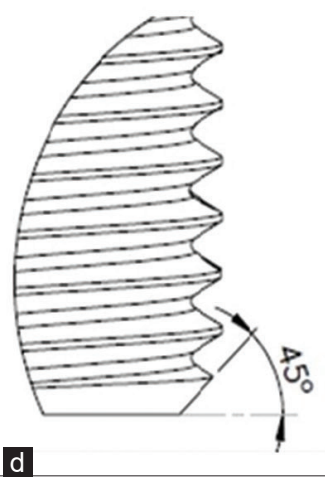

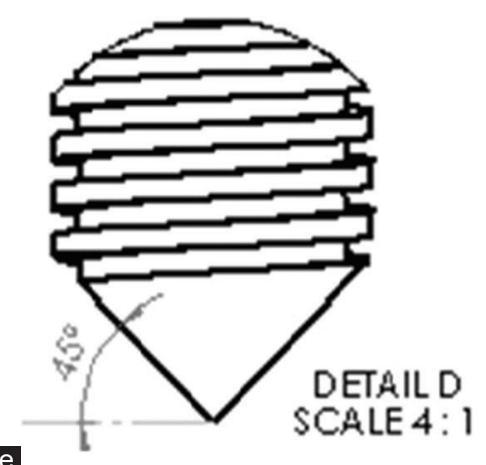

Figure 1: The five tooth profiles (a) Curved tooth with 1.2P, (b) Inclined cut tooth with 1.5P, (c) Trapezoidal tooth with 1.8P, (d) Saw tooth with chamfered 


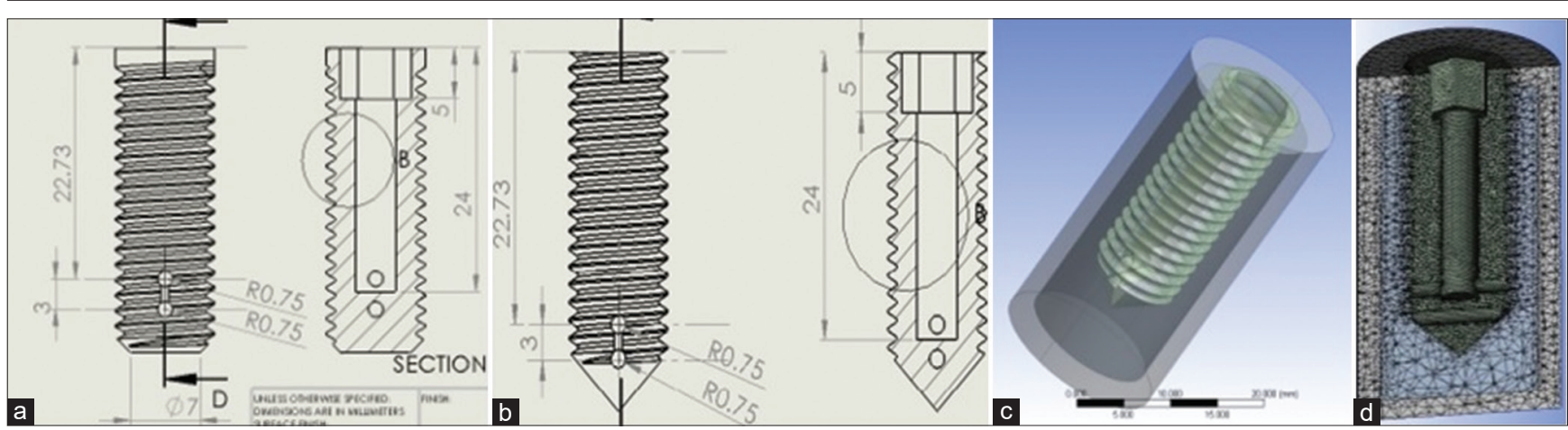

Figure 2: (a-d) Sample of the analyzed models and meshed parts from ANSYS workbench screen

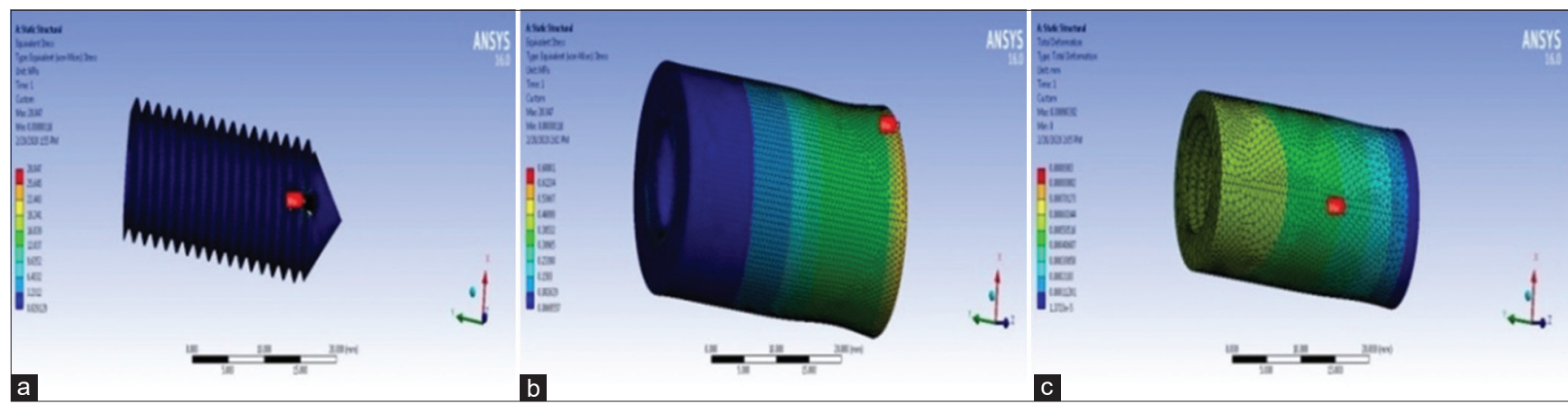

Figure 3: Sample results as ANSYS screen shots for model with curved teeth of $1.5 \mathrm{~mm}$ pitch and tapered tip, where (a) Anchor Von Mises stress, (b) Cortical bone Von Mises, (c) Spongy bone total deformation

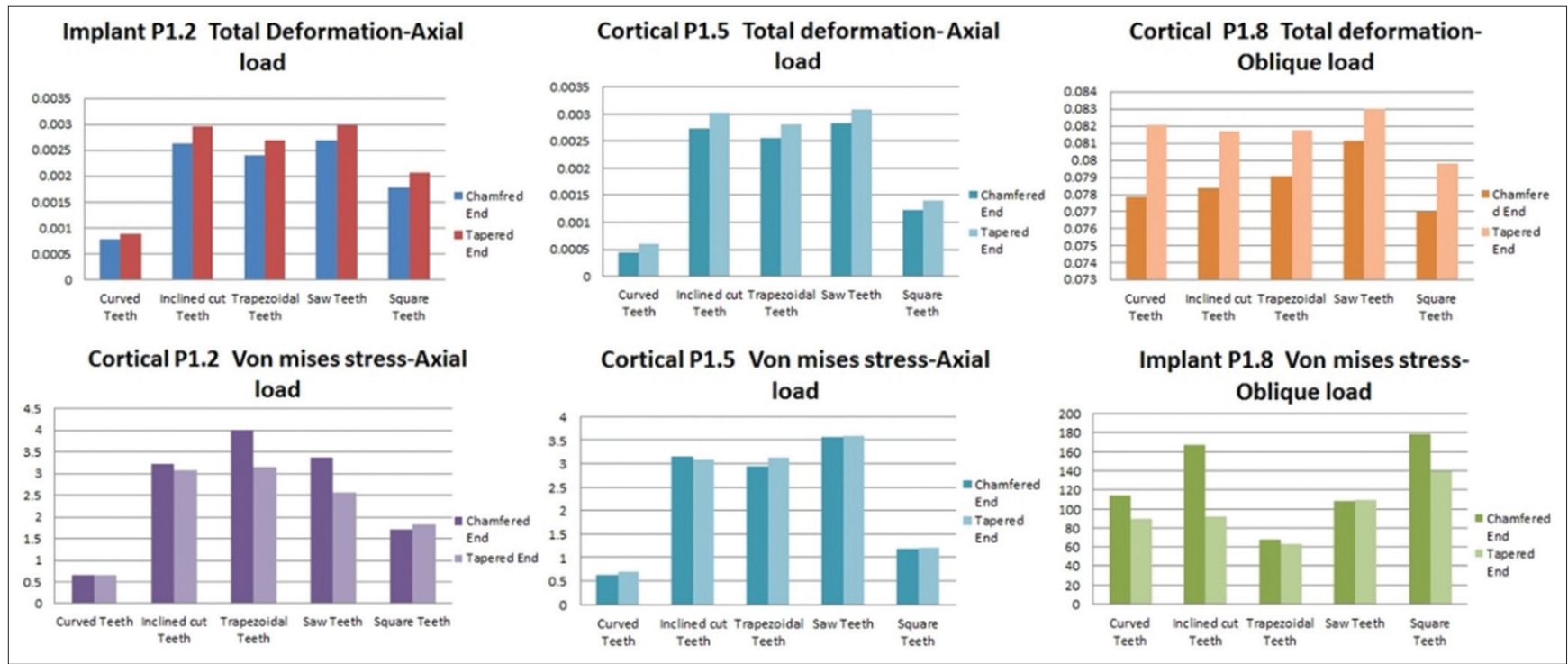

Figure 4: For all thread profiles; Comparison between total deformation and maximum Von Mises stress on cortical bone and anchor body with different pitches under both loading conditions

profiles in comparison to the other ones under vertical loading from total deformation and Von Mises stress perspectives. The differences between these thread profiles tend to vanish by increasing pitch. Whatever the case is, using anchor with tapered tip profile causes slight or negligible increase in total deformation and Von Mises stress.

Comparing pitch length effect for each thread profile (Figure 5), showed negligible slight/differences in total deformation and Von Mises stress. In the majority of designs pitch of $1.5 \mathrm{~mm}$ exerts less stresses on cortical bone. Another confirmation of slight increasing of stresses and deformation with tapered end profile above chamfered one.

\section{Discussion}

The HiFi and stainless steel wires of $0.5 \mathrm{~mm}$ were cut inside the anchor at tensile load lower than 


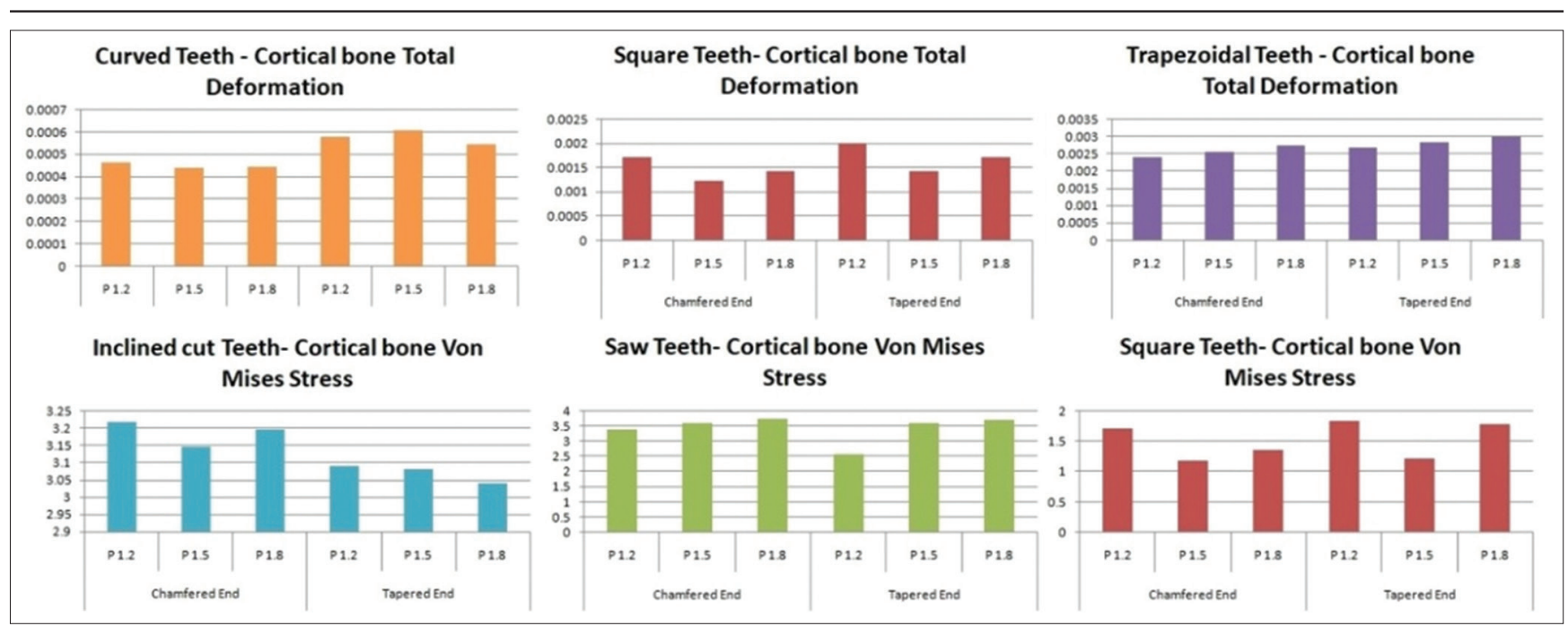

Figure 5: For each thread profile; comparison between total deformation and maximum Von Mises stress on cortical bone and anchor body with different pitches under both loading conditions

$280 \mathrm{~N}$ during tensile test, and no failure was noticed on the anchors body [19]. Therefore $300 \mathrm{~N}$ applied load as vertical and oblique was selected for this study. Failure may occur at the suture level, suture anchor, bone, and soft tissue. Anchors are designed for suture pull along the insertion axis, while the eyelet is designed rounded or streamlined with channels that protect the suture [20], [21], [22]. According to in vitro tests all sutures were failed at around $280 \mathrm{~N}$. That matches previous studies by Aktay et al. and Er et al. [5], [23], that find it of order $300 \mathrm{~N}$. Suture-anchor interface is a common area of failure with metallic anchors where the suture is serially abraded by the anchor's eyelet [19]. The design of the eyelet, surface roughness, and arc of contact between the eyelet and suture all contribute to the created frictional resistance. Greater friction leads to a lower maximal breaking strength of the suture. The failures occurred in most instances by rupture of the suture material. For metal anchors, threads almost always ruptured at the eyelets of the anchors [23].

This study results showed that reducing thread pitch, slightly decreases stresses on cortical bone. That may be referred to increasing contact areas between anchor and cortical bone. On the other hand, decreasing the pitch showed an improved effect on the implant itself by increasing the material around the eyelet. For an anchor, the less was the pitch the more will be the bearing area, but will not perform well because the threads are too close together to effectively engage the trabeculae [22] Yakacki et al. [22]. The deeply inserted threads likely increased the pullout force past the predicted range based on a smaller nominal insertion depth. The Bio-Corkscrew (Arthrex, Naples, Florida, USA) strength was consistently higher than the Opus Magnum, but this was simply due to the larger device size (5 vs. $3 \mathrm{~mm}$ ) and larger corresponding bearing area [22].

The finite element analyses on all models under both loading conditions showed stresses within physiological limits on the bone with all tested models. Trapezoidal teeth and inclined cut teeth designs showed the lowest values of stresses and deformations respectively on the bone under oblique loads, while curved tooth and square tooth designs showed the lowest values of stresses and deformations, respectively, on the bone under vertical loads.

Thread profile showed a moderate effect on implant body itself, which may not referring to the design rather than increasing material around the eyelet. Thread profile might generate thin sites or sharp edges at the interface with cortical bone, this may cause stresses increase on cortical bone.

A screw of equal proportion but greater size will possess a higher strength than its smaller counterpart, comparing screws with different thread designs and sizes is difficult because of different bearing area than the regular version [22]. The anchor has a short body with deep threads that secure it into the bone allowing decent holding strength. Finally, anchor tip angle has negligible effect on anchor body, cortical and spongy bone.

Anchor tip profile results showed negligible effect on both cortical bone and anchor body. This finding matches previous study by El-Anwar et al. [19].

\section{Conclusions}

According to this study and within limitations it can be concluded that:

- $\quad$ Thread profile has slight impact on bone, while it may reduce stresses on anchor body if it placed more material around the eyelet. Increasing thread pitch of arthroscopic suture anchors increases or decreases stress on 
bone, and anchor body according to thread profile edges.

- $\quad$ Anchor tip profile has insignificant influence on both deformations and stresses on bone and anchor body.

\section{References}

1. Azato FN, Yamasaki AT, Sucomine F. Traction endurance biomechanical study of metallic suture anchors at different insertion angles. Acta Ortop Bras. 2003;11(1):25-31. https://doi. org/10.1590/s1413-78522003000100004

2. Schwitalla A, Muller WD. PEEK dental implants: A review of the literature. J Oral Implantol. 2013;41(6):743-9. PMid:21905892

3. Najeeb S, Khurshid Z, Matinlinna JP, Siddiqui F, Nassani MZ, Baroudi K. Nanomodified PEEK dental implants: Bioactive composites and surface modification-a review. Int J Dent. 2015;2015:381759. https://doi.org/10.1155/2015/381759 PMid:26495000

4. Suture Anchor Assembly, United States Patent No. 4, 632, 100; 1986.

5. Aktay SA, Kowaleski MP. Analysis of suture anchor eyelet position on suture failure load. Vet Surg. 2011;40(4):418-22. https://doi.org/10.1111/j.1532-950x.2011.00834.x PMid:21539579

6. Hughes CM. A Finite Element Modelling Strategy for Suture Anchor Devices. PhD Thesis, School of Engineering and Design, Brunel University; 2014

7. Suture Anchor and Driver Assembly, United States Patent No. 5 , 100, 417; 1992.

8. Bone Screw, United States Patent No. 5, 169, 400; 1992.

9. Suture Anchor Assembly, United States Patent No. 5, 370, 662; 1994.

10. Bone Screw with Improved Threads, United States Patent No. 5, 417, 533; 1995.

11. El-Anwar M. Second Annual report on Redesign of Some Endoscopic Instruments and Implants (GIT and Joints). Egypt: National Research Centre.
12. International Organization for Standardization. Safety AspectsGuidelines for their Inclusion in Standards, ISO/IEC Guide No. $51 ; 2014$

13. International Organization for Standardization. Biological Evaluation of Medical Devices-Part 12: Sample Preparation and Reference Materials, ISO No. 10993-12; 2012.

14. International Organization for Standardization. Medical Devices-Application of Risk Management to Medical Devices, ISO No. 14971; 2007.

15. European Committee for Standardization (CEN). Medical Devices-Application of Risk Management to Medical Devices, EN ISO No. 14971; 2012.

16. International Organization for Standardization. Biological Evaluation of Medical Devices-Guidance on the Conduct of Biological Evaluation within a Risk Management Process, ISO TR No. 15499; 2012. https://doi.org/10.3403/30211401

17. Meyer DC, Nyffeler RW, Fucentese SF, Gerber C. Failure of suture material at suture anchor eyelets. Arthroscopy. 2002;18(9):1013-9. https://doi.org/10.1053/jars.2002.36115 PMid:12426545

18. Barber FA, Herbert MA, Beavis RC, Barrera Oro F. Suture anchor materials, eyelets, and designs: Update 2008. Arthroscopy. 2008;24(8):859-67. https://doi.org/10.1016/j.arthro.2008.03.006 PMid: 18657733

19. El-Anwar M, Osman W. Finite element study on arthroscopic anchor design aspects. Open Access Maced J Med Sci. 2019;7(4):628-31. https://doi.org/10.3889/oamjms.2019.164 PMid:30894926

20. Wright PB, Budoff JE, Yeh ML, Kelm ZS, Luo ZP. Strength of damaged suture:An in vitrostudy. Arthroscopy. 2006;22(12):12705. https://doi.org/10.1016/j.arthro.2006.08.019 PMid: 17157724

21. Barber FA, Herbert MA, Click JN. Internal fixation strength of suture anchors-update 1997. Arthroscopy. 1997;13(3):355-62. https://doi.org/10.1016/s0749-8063(97)90034-7 PMid:9195034

22. Yakacki CM, Griffis J, Poukalova M, Gall K. Bearing area: A new indication for suture anchor pullout strength? J Orthop Res. 2009;27(8):1048-54. https://doi.org/10.1002/jor.20856 PMid:19226593

23. Schneeberger AG, Von Roll A, Kalberer F, Jacob HA, Gerber C Mechanical strength of arthroscopic rotator cuff repair techniques: An in vitro study. J Bone Joint Surg. 2002;84A(12): 2152-60. 